\title{
KONDRATIEV GYCLES AND SO-CALLED LONG WAVES
}

\section{The early research}

\author{
J. Tinbergen
}

This paper recalls some early work of the Dutch pioneers of long-wave research which anticipated many of the contemporary debates. Various explanations which have been advanced for the existence of long waves are reviewed, and the applicability of long-wave theories in a number of contexts is examined.

IN THE 19 th and 20 th centuries-ie from the beginning of industrialisationseveral statistical time series have shown rising and declining movements, which could be interpreted as waves with a period of about 40 years. This applies clearly to the index numbers of wholesale prices, and also to the prices of wheat. Deviations from trends in many production series and interest rates are other examples of series showing wave-like movements. These fluctuations reached their highest points about 1870, 1920, and 1970, and their lowest points about 1850 and 1895 .

Precise identification of these turning points is not possible because of disturbing influences caused by World Wars 1 and 2. The Dutch economist $J$. van Gelderen ${ }^{1}$ (writing under the pen-name J. Fedder) was the first author to draw attention to these wave-like movements. In the international literature the Russian economist N.D. Kondratiev ${ }^{2}$ is generally credited with the discovery of the long waves. ${ }^{3}$ The register of Schumpeter's book does not even mention the names of Fedder or van Gelderen. On the other hand, Wesley C. Mitchell ${ }^{4}$ gives full credit to van Gelderen and S. de Wolff for their pioneering research into long waves, which he explains in considerable detail.

\section{Waves}

The alternation of rising and declining movements can be regarded as waves, Professor J. Tinbergen is Emeritus Professor of Economics at Erasmus Universiteit, Rotterdam, Postbus 1738, 3000 DR, Rotterdam, The Netherlands. 
meaning that successive phases are connected by a causal mechanism or a logical interrelationship. Those who adhere to this interpretation prefer to speak of 'waves', or more precisely 'long waves', because the existence of two or three shorter cycles has been established, including the so-called business cycle, also called a 'Juglar' after the French economist who discovered it.

Those who are not yet convinced of the existence of a causal relationship between the various phases are inclined to avoid the use of the term 'waves', and prefer to speak instead of 'so-called long waves'.

\section{Monetary theories}

Various explanations of the long waves have been given. The first attempts at explanation were based on monetary theory. They emphasise the parallelism between the fluctuations in prices and in the total stock of monetary gold. ${ }^{5}$ Movements in the gold stock have been influenced by various factors and by the discovery of new gold fields. If one agrecs that these discoveries wcre largely a matter of chance, then the concept of a 'wave' would not play a role in this context. If, on the other hand, one takes into account that the production of gold is influenced by its price, then there is room for a systematic factor in the movements of the total stock of gold.

Whatever the case may be, the explanation is no longer of importance for practical policy, because the members of the International Monetary Fund (IMF) have agreed that in principle total money circulation should not depend solely on the gold stock (and according to others not at all). Instead it depends partly, and in future wholly, on the Special Drawing Rights (SDRs) allotted by the IMF to the various central banks. We have freed ourselves from the discoveries of gold fields and production plans (mainly of South Africa and the USSR) as determining factors, or at least we are on the road to greater freedom.

\section{Investments for replacement}

Other economists have tried to explain 'long waves' on the basis of the investment decisions of business enterprises. Two different theories can be distinguished which are important for the choice of a policy aimed at the gradual elimination of the long waves.

In the analysis of investment a distinction is made between replacement of existing capital goods, and new or autonomous investments. The first occurs when an existing capital good (building, machinery, vehicle, etc) goes out of use and must be replaced by a newly produced unit. The second type of investment (new or autonomous) occurs when someone starts a new production, ie enlarging the existing capacity for the output of known products, or when he starts producing entirely new products, such as the first vacuum cleaners, radiu sets, television sets, or satellites.

Replacement investment will occur when there is no longer a profitable use for existing equipment. In an extreme technical sense this is the case, for instance, when a truck is destroyed in a road accident; in a less extreme sensc when a machine is used up through wear and tear, or when a building has become dilapidated beyond repair. 
In an economic sense replacement will be necessary also if the equipment has become obsolete, ie when it can no longer compete with equipment from more modern 'vintage years'. The new 'vintages' are usually cheaper in the productive process either because of the introduction of improvements, or because less labour is required. The Central Planning Bureau of the Netherlands attributes considerable importance to this type of economic obsolescence.

Reinvestments build a link with the remaining stock of capital goods from the past. Thus they may contribute to a theory of a wave. The theory which explains the long waves (and also the Juglar) with the help of investments for replacement is called the theory of the echo-principle, and has been advanced by $S$. de Wolff. ${ }^{6}$ De Wolff distinguishes two types of capital goods, with an average length of life, respectively, of 40 years and about eight years. If, because of an accidental cause in a period $t$ (of several years duration), a large number of capital goods with a life expectancy of $T$ years is produced, then demand for replacement will be larger in the period $t+T$, and again $T$ years later. Upper levels of reinvestment will be reached after periods of $T$ years. Capital goods with a length of life of about 40 years include rolling stock of the railways according to figures published by the Netherlands Central Bureau of Statistics.

\section{Technical and economic length of life}

The theory of the echo-principle has been discussed in several works, notably in the volume of essays published in honour of de Wolff in 1938.8 The discussion was concerned mainly with the possible effects of the large variations in technical lifetimes according to figures assembled by $\mathrm{H}$. Vos. ${ }^{9}$

Starting from one year $t$ with a large production of the category of capital goods considered, and assuming replacement after a technical lifetime of $T^{\prime}$ years, the first echo shows a very flat curve only (around the year $t+T^{\prime}$ ), and hardly a second echo. If, on the other hand, one takes into account that not the technical but the economic lifetime is decisive for replacement, it can be shown that waves with unchanged amplitudes are possible. ${ }^{10}$

It should be mentioned that de Wolff did not consider the initial high output in the year $t$ as accidental, but as a result of a preceding more agrarian phase in the development of society which experienced years of large crops and of smaller crops, and consequently of low and high prices of cereals. These waves werc probably influenced by the periodicity of sun spots. Although many questions about these cosmic influences on crops have remained unanswered, the elegance of the theory is not to be denied.

\section{Life cycles or lag cycles?}

Compared to competing business cycle theories, the echo principle has another advantage which applies to the Juglar with a possible extension to the long waves. The competing theories may be summarised as based on lag cycles. They have in common that a cyclical movement may develop if a time lag exists between the reaction of supply of a commodity to changes in its price. Well known examples which have been widely discussed are the markets for pigs, coffee and ships. 
With respect to the market for pigs, it could be concluded, briefly, that after a period of high prices (or low prices) the supply of pigs would be high (low) about $1 \frac{1 / 2-2}{2}$ years later. This time lag is due to psychological and commercial reactions of the farmers, and the length of the biological process to 'produce'

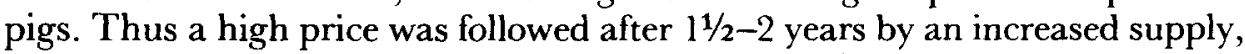
which could be sold only at reduced prices. Again 11/2-2 years later supply was at a reduced level, and prices went up. The length of the cycle was $3-4$ years, ie twice the time lag between price and supply. ${ }^{11}$

On the market for coffee, ${ }^{12}$ a high price resulted after $6-7$ years in an increased supply, because it encouraged increased planting of coffee trees. This development depressed coffec prices, but the trend continued because a coffee tree remains productive during a number of years, contrary to what happens in the case of pigs.

In the case of ships the situation was roughly the same. After a year of high freight rates more new ships were ordered, and after about a year these vessels were launched. Thus thcy tended to depress freights, and would continuc to do so as long as they kept running-on an average about 17 years for a Dutch shipowner, often succeeded by low-cost operators for another 17 years.

A mathematical analysis reveals that the resulting waves have a length equal to about four times the time lag involved. ${ }^{13}$ In more complete models of a country's cconomy as a whole, which include variables such as total production and total consumption, imports and exports, their prices etc, other time lags occur, for instance between income and consumption expenditure, and between profits and investment. Usually these time lags do not exceed about one year, but they can help to explain cyclical movements with a wave length of about cight years.

A disadvantage of this explanation of the ordinary business cycle is that small changes in the time lags mentioned may entail lai ge changes in the length of the waves. However, the statistically observed waves, though far from regular, show wave lengths which are rather constant. The sensitivity of the waves determined by the length of life of capital goods 's less, and this is an argument in favour of the theory based on the reinvestments.

\section{Waves by autonomous new investments?}

As was mentioned above, new investments are frequently caused by the discovery of new products and new methods of production. A number of economists have interpreted these developments as the causes of the long waves. They claim that important discoveries have occurred in certain periods, but much less so in between. As an example they mention the discovery and thereafter the application (this is what matters) of the steam engines, which around 1800 made industrialisation possible in England. Other examples are the introduction of steamships which after 1870 contributed largely to the transport of cereals across the Atlantic Ocean, of electricity, which caused steam'engines to be replaced by electromotors, and a number of discoveries and innovations in chemistry, which greatly stimulated the growth of chemical industries. The discovery of the internal combustion engine-and therefore of the automobile--should also be mentioned. 
The difficulty with this approach is, first, that it is not easy to define a measure of the importance of discoveries. Moreover, the question may be put whether accidental factors play a role here, and then we could not speak of true waves. With regard to the present, the economists mentioned hope for a new 'important' discovery to help us out of the deep depression which has been dragging on. Attention is focused on microprocessors: although it is not possible to make predictions, clearly they could exert an important influence on production and employment. On the other hand, there is every reason to question whether only technical innovations can bring about large-scale economic recovery. Could not social changes on a worldwide scale have a similar effect? Are we not able to control these social innovations ourselves, as in the case of the SDRs, which have replaced gold? There could be major advantages in, for instance, a much more vigorous development policy for the Third World.

Furthermore, strong arguments could be advanced in favour of accelerated programmes for scientific research. The projects of vital importance for the future of all include the following:

- How will the use of fossil fuel affect the climate?

- Which part of the total area of the globe should remain free and unobstructed nature?

- What risks are involved in the production of various types of energy?

- How could labour satisfaction be improved by alternative types of work?

At a large number of institutes research is underway on these and many other projects. How could this research be accelerated, coordinated, and financed? In doing this, how could we avoid more inflation?

\section{Is there a causal link between new investments and preceding phases?}

Returning once again to the new investments, should one consider them after all as being caused by the preceding long depression, instead of being autonomous and accidental? The longer the depression lasts, the more certain it is that enterprises and technicians will study new possibilities in an effort to set the industries on their feet again. If indeed this should be the case, then this explanation of rising and declining long-term movements would result in a wave, and therefore necessarily in a return to prosperity. Perhaps these aspects of the problem deserve more attention and can be added to our list of vital projects.

The most modern methods of research into the long-term movements include the work of J. Forrester. ${ }^{14}$ In his case (and that of many other modern quantitative research workers) rather complicated, interdisciplinary, and mathematically formulated models are used, which cannot be considered fully within the context of a short article. Those authors should be considered as pioneers in a new and largely unknown domain. Interested readers are referred, for instance, to the work by P. Nijkamp et al. ${ }^{15}$ 


\section{Notes and references}

1. J. van Gelderen, "Springvloed : beschouwingen over industrieële ontwikkeling en prijsbeweging", in De Nieuwe Tijd, 1913, 18.

2. N.D. Kondratiev, "Die langen Wellen der Konjunktur", Archiv für Sozialwissenschaft, December 1926, LVI, pages 573-609.

3. J.A. Schumpeter, Business Cycles (McGraw-Hill, 1939), page 164.

4. Wesley C. Mitchell, in Business Cycles, Volume I (National Bureau of Economic Research, 12th imprint, 1936), pages 227-929

5. S. de Wolff, Het economisch getij (Amsterdam, J. Emmering, 192S, page 431.

6. Ibid.

7. Netherlands, Central Bureau of Statistics, De Nederlandsche Conjunctuur (1934), pages 22 and 37.

8. J. van der Wijk et al (eds), Strijdenskracht door Wetensmacht (Amsterdam, 1938).

9. H. Vos, "Over de levensduur van machines en gebruiksgoederen", in ibid, pages 117-132.

10. J. Tinbergen, Selected Papers (Amsterdam, North Holland, 1959), pages 85-92; see also J. Tinbergen and J.J. Polak, The Dynamics of Business Cycles (Chicago, 1950), pages 155-158, 178-180, 202, and 230.

11. H. Hanau, "Die Prognose der Schweinepreise", Sonderheft 2, zu den Vierteljahresheften zur Konjunkturforschung (Berlin, 1928).

12. H. Roth, Die Übererzeugung in der Welthandelsware Kaffee im Zeitraum von 1790-1929 (Jena, Gustav Fischer, 1929).

13. J. Tinbergen, "Tonnage and freight", in Tinbergen, reference 10, pages 93-111.

14. J.W. Forrester, World Dynamics (Cambridge, MA, Wright-Allen, 1971).

15. P. Nijkamp et al, Multidimensional Spatial Data and Decision Analysis (New York, Wiley, 1979). 